\title{
Herbivory and local genetic differentiation in natural populations of Arabidopsis thaliana (Brassicaceae)
}

\author{
Asghar Mosleh Arany • Tom J. de Jong • \\ Ed van der Meijden
}

Received: 8 September 2008/ Accepted: 13 October 2008/Published online: 2 November 2008

(C) The Author(s) 2008. This article is published with open access at Springerlink.com

\begin{abstract}
To explore genetic variation in defence against the natural herbivores of Arabidopsis thaliana, we transplanted genotypes between a dune habitat and inland habitat in both of which A. thaliana occurred naturally. In previous years we had observed that the specialist weevils Ceutorhynchus atomus and $C$. contractus (Curculionidae) fed conspicuously on flowers and fruits of A. thaliana in the dunes, while these weevils were always rare in inland habitats. Taking all plants together, total fruit damage was indeed much higher in our experimental plots in the dune habitat $(59.7 \%)$ relative to the inland garden habitat $(18.9 \%)$. Within a habitat, additional differences existed between plants of different origins, pointing to genetic differences in ecologically relevant characters; plants of inland origin flowered a week earlier, grew better and produced more fruits than plants of dune origin. However, plants of inland origin experienced more total fruit damage by the specialist weevils (75.4\%) than plants of dune origin $(44.0 \%)$ when the two types grew side by side in the dune habitat. Escape from herbivory gives dune
\end{abstract}

\footnotetext{
A. Mosleh Arany

Faculty of Natural Resources \& Desert, Yazd University, 89195-741, Yazd, Iran

T. J. de Jong $(\bowtie) \cdot$ E. van der Meijden Institute of Biology Leiden, University of Leiden, P.O. Box 9516, 2300 RA Leiden, The Netherlands e-mail: t.j.de.jong@biology.leidenuniv.nl; dejong@rulsfb.leidenuniv.nl
}

genotypes an advantage in their native habitat, whereas stronger growth and higher survival gives inland genotypes an edge under garden conditions.

Keywords Adaptation - Plant defence . Reciprocal transplantation $\cdot$ Ceutorhynchus

\section{Introduction}

Adaptive genetic variation in plants has been convincingly demonstrated in relation to abiotic factors, like elevation (Clausen et al. 1940, 1948; Gurevitch et al. 1986), latitude (Mooney and Billings 1961), heavy metals (McNeilly and Antonovics 1968), water availability (Farris 1987), soil type (Snaydon 1970) and salinity (Antlfinger 1981). Biotic factors have received less attention. Turkington and Harper (1979) and Schoen et al. (1986) studied genetic variation in relation to competition, while other studies examined plant pathogen interactions (Kaltz et al. 1999; Thrall et al. 2002). Whether herbivores can cause local adaptation in plants is relatively unknown (but see Prins 1989; Linhart and Grant 1996; Valverde et al. 2003; Nunez-Farfan et al. 2007). Herbivory can have a strong effect on plant fitness and if herbivore pressures differ consistently between habitats in the field, this could well select for plant characters that avoid or reduce herbivory. Whether this occurs in 
nature, or that abiotic factors are more important for adaptation, remains to be seen.

Arabidopsis thaliana (L) Heyn. (Cruciferae) is a small annual plant of Eurasian origin, which is now widely distributed in many parts of the northerntemperate zones of the world (Ratcliffe 1961). Arabidopsis thaliana shows a wide climatic amplitude, which makes it suitable for analysing variation in adaptive traits (Koornneef et al. 2004). While homozygosity within populations is high in this predominantly selfing species (Bergelson et al. 1998), genetic differences among Eurasian populations are apparent (Nordborg et al. 2005, see also Jorgensen and Mauricio 2004, for a comparison with Northern America). Several studies have used among-population variation to study fitness consequences of herbivore resistance (Mauricio 1998; Weinig et al. 2003; Murren et al. 2005) and other traits (Griffing and Scholl 1991; Pigliucci 1998; Nordborg and Bergelson 1999; Mitchell-Olds 2001; Pigliucci and Marlow 2001; Kover and Schaal 2002; Koornneef et al. 2004). However, most of these studies typically used a large set of accessions, randomly selected from the species' range. It is still unknown how much genetic variation exists when comparing A. thaliana populations at a small scale between habitats that are ecologically different. It is also unclear how well A. thaliana, or any other species, can adapt against specialist herbivores that are under continuous strong selection to break its defence (van der Meijden 1996).

While common garden and greenhouse experiments have shown significant variation in the resistance traits in A. thaliana (Weinig et al. 2003; Griffith et al. 2004), they do not fully address the potential adaptive nature of genetic variation (Rice and Mack 1991). In several such studies, different genotypes were raised in a single common garden (for instance, Weinig et al. 2003; Griffith et al. 2004) or herbivores were used that probably have little impact on A. thaliana in the field (Harvey et al. 2007). However, common garden studies may miss relevant ecological factors that vary at a small scale. For instance, naturally occurring herbivores, specialists in particular, are likely to be present in low numbers when a new garden population is established and their populations may build up over time. As a result effects of specialist herbivores are likely to be underestimated in such studies. Reciprocal transplants in established field populations are more realistic for addressing the question of local adaptation (Antonovics and Primack 1982).

This study is based on the observation that in a dune habitat in the Netherlands the specialist weevils Ceutorhynchus atomus and C. contractus (Freude et al. 1983) feed frequently on A. thaliana, while in other habitats the weevil is rarely observed. By comparing plants covered with a net with uncovered control plants, we found that weevils reduced seed production by $40 \%$ in the dunes (Mosleh Arany et al. 2005). This situation provides a unique opportunity to study differences in plant defence, especially with respect to defence against a specialist herbivore.

In this study we swap A. thaliana genotypes between one dune site (high herbivory) and one inland site (low herbivory). We address the following questions: (1) Is variation in growth and herbivory in the field due to genetic differences between populations or environment?, (2) Do home genotypes outperform foreign genotypes? and (3) Do herbivory levels differ between plants from dune and inland origin?

\section{Materials and methods}

\section{Habitat description}

Arabidopsis thaliana can be found in the coastal regions of the Netherlands, where it grows in two habitat types. This species occurs locally on the calcareous new dunes that were formed partly on top of the old soil profile c. 800 years ago (called dune hereafter). It is also locally common on disturbed roadsides in the west of Holland (called inland hereafter). The former is a natural habitat for A. thaliana in the sense that it was not recently created by large-scale anthropogenic disturbance and presumably plants have been evolving under similar conditions over many hundreds of generations.

Our study area in the dunes was located in Meijendel, north of The Hague (the Netherlands), where we sampled seeds from three local populations. Population 1 and 2 were only $5 \mathrm{~m}$ apart and the third one was separated from the other two by $500 \mathrm{~m}$. Humus content of the top $10 \mathrm{~cm}$ of the soil is low (between 0.45 and $0.96 \%$ in the top $10 \mathrm{~cm}$ ) and consequently the dune sand is infertile with a low water holding capacity. The sandy surface at the dunes sites was covered with moss, grasses and small herbs 
with about $10 \%$ bare soil. Accompanying species included, among others, Erophila verna, Cardamine hirsuta, Rubus caesius and Calamagrostis epigejos. All populations in the dunes were found within $20 \mathrm{~m}$ of woody vegetation with small Hippophae rhamnoides shrubs and trees such as Populus nigra, P. alba, Betula pubescens and Crataegus monogyna.

For inland habitats seeds were collected along a roadside at the edge of Leiden (population 1) and next to a small canal in Noordwijk (population 2). Humus content was high compared to the dune populations (see above): inland population 1 had $1.18 \%$ and population 2 had $1.62 \%$ humus in the top $10 \mathrm{~cm}$ of the soil. Both sites were covered with Lolium species, leaving small open patches for the herbs. Accompanying species included, amongst others, Erophila verna, Cardamine hirsuta and Plantago lanceolata. The distance between the two inland populations is about $8 \mathrm{~km}$ and the minimal distance between the dune and the inland habitat is about $6 \mathrm{~km}$ (Mosleh Arany 2006).

\section{Herbivores}

We observed Ceutorhynchus beetles conspicuously feeding on A. thaliana flowers, especially on the carpels, and ovipositing in the developing fruit. Many of the fruits contained beetle larvae after opening. We collected adult beetles from the flowers and all were identified by Dr. Th. Heijerman (Biosystematics Group of Wageningen University) as either Ceutorhynchus atomus or C. contractus. Based on observations made three times per week during the flowering period, we concluded that these beetles caused most of the observed damage to flowers and fruits. However, some herbivory by some rare additional herbivore species cannot be excluded. Voucher specimens of the beetles have been deposited at the National Museum of Natural History Naturalis in Leiden (the Netherlands). The RMNH.INS registration numbers are $050 \quad 001$ and $050 \quad 002$ for C. contractus and 050003 and 050004 for C. atomus (contact person at Naturalis A. van Assen).

The beetles cause two types of damage that follow each other in time. First, direct herbivory on the flowers by the adult beetles causes some flowers not to develop fruit. Second, beetles also oviposit in developing fruit and the developing larvae then feed on the fruit contents, after which they leave the fruit, fall to the ground and survive as pupae until the next spring. The damage caused by larvae is evident after opening of the fruits. We find that adults feed mostly on flowers and oviposit in developing fruits in which the larvae develop. This behaviour is different from the description of Freude et al. (1983), who emphasized that the weevils induce galls in A. thaliana (C. atomus) or mine leaves (C. contractus). When we took beetles from the field and placed them on flowering Arabidopsis plants in the greenhouse, the beetles climbed the plants and began feeding on the flowers where they stayed most of the time. Later on beetle larvae emerged from the fruits. When adult beetles were placed on vegetative plants, they did feed on the leaves.

The weevils, Ceutorhynchus atomus and C. contractus (Curculionidae), are common in disturbed, sandy habitats in the Netherlands. While C. atomus is found and reported throughout the Netherlands, C. contractus occurs mainly in the coastal areas of the Netherlands (T. Heijerman, personal communication, 2006). As far as we know, these common European species have not been reported in the US.

\section{Transplant experiment}

In three dune and two inland populations we randomly selected ten plants per population. In July 2002 seeds were collected from each plant. To reduce maternal effects, plants were grown for one generation under controlled conditions in a growth chamber (potting soil, $20^{\circ} \mathrm{C}, 18 \mathrm{~h}$ light, $70 \%$ humidity and 2 months in a cold room at $4^{\circ} \mathrm{C}$ at the rosette stage). Seeds resulting from self-pollination were kept at room temperature until October 2003 when they were germinated. Rosettes (diameter $2 \mathrm{~cm}$ ) were then transplanted into an enclosure of $16 \mathrm{~m}^{2}$ at the dunes close to dune population 3 and a second enclosure in a common garden at Leiden, close to inland population 1. Enclosures had a large mesh size $(1.5 \mathrm{~cm})$ and kept people and grazing cattle out, while allowing small herbivores free access to all plants. We were not allowed to set up an enclosure at the original inland sites but consider the chosen garden site in Leiden to be similar to the two inland sites: the garden site had a humus content of $1.0 \%$ and A. thaliana grew there naturally. For each of the 5 populations, seeds from 10 plants were germinated and for each parent plant 8 small rosettes were 
transplanted into each of the 2 enclosures. Hence, a total of 800 plants were transplanted. Within each enclosure, rosettes were positioned at $10-\mathrm{cm}$ intervals. The rosettes were transplanted with potting medium adhering to the roots and with minimal disturbance to the surrounding vegetation. Survival (from rosette stage to seed production), morphological characteristics such as rosette size, stem number and plant height were measured before harvesting the plants in May 2004.

To estimate seed production of the damaged plants we used the following method. When flowering ended we harvested the plants and measured the number of flowers without a fruit (A), with an infested fruit (B) and with an undamaged fruit $(\mathrm{C})$. We interpret the fraction of all flowers that did not produce fruit (A/ $(\mathrm{A}+\mathrm{B}+\mathrm{C}))$ as the flower damage caused by adult beetles. This is consistent with the observation in the previous year (2003) that, when beetles were kept away from plants, all flowers produced fruit (Mosleh Arany et al. 2005). The fraction of damage caused by beetle larvae is $\mathrm{B} /(\mathrm{A}+\mathrm{B}+\mathrm{C})$. The total fraction of herbivore damage is the sum of the fraction of flowers eaten by the adult beetles fruits plus the fraction of flowers with fruits containing a larvae $((\mathrm{A}+\mathrm{B}) /$ $(\mathrm{A}+\mathrm{B}+\mathrm{C}))$. To estimate the number of seeds produced, rather than the number of fruits, we assumed that the fraction of seeds eaten by larvae in an infested fruit is $80 \%$ (Mosleh Arany et al. 2005) and is the same for plants of all origins. Fitness was then estimated as plant survival until reproduction multiplied by units of intact fruits produced after herbivory had taken place [fitness $=$ survival $\times$ (intact fruit $+0.2 \times$ fruit damaged by larvae); each fruit damaged by larvae counted as 0.2 units of intact fruit]. For comparing the genotypes we assumed that the genotypes have similar numbers of seeds per intact fruit. Because we planted seedlings of different origin, our fitness measure does not include possible differences in seedling germination and survival of seedlings.

All data were analyzed with SPSS 15 (SPSS Inc., Chicago, USA). We first performed a statistical analysis on the data of individual plants. This analysis was complex because residuals were overdispersed. To improve normality, we decided to simplify the analysis by taking the average of all surviving (8 maximum) seedlings from the same mother plant. We then used these averages as dependent variable in the Generalized Linear Model. Main effects include the site where plants were grown (dunes or garden) and the origin of the plant (dune/inland). The specific population from which the plants were derived was nested with origin. After log-transformation all residuals fitted well to a normal distribution.

\section{Results}

Site effects

A significant effect of the site where plants are grown existed for all traits examined (see Generalized Linear Model in Table 1). This simply reflects that all plants grew much better in the garden; the number of stems, stem height and the number of fruits (before and after herbivory) were highest when plants were grown in the inland garden (Fig. 1). In addition, the percentage of damage by adult weevils and their larvae was typically lower when plants grew in the inland garden (Fig. 1e, f). For plants of dune origin, total $\%$ fruits with herbivory was $44.0 \%$ in the dunes and $17.3 \%$ in the inland. For plants of inland origin, total \% fruits with herbivory was $75.4 \%$ in the dunes and $20.6 \%$ in the inland.

\section{Origin effects}

A significant effect of origin of the plants existed for all measured traits (Table 1), indicating genetic differences between plants originating from dune and inland. The effect of population within origin is only significant for percentage damage caused by weevil larvae; for all other measured traits the population effect is not significant. This shows that within the dune or inland origin the populations are quite similar.

Plants from inland origin typically produced more stems (Fig. 1a) and more fruits in total (Fig. 1c) but were more heavily damaged by weevil adults (Fig. 1e) and larvae (Fig. 1f). Plants from dune origin survived better than those from inland origin, but the effect was only significant at the dune site (Chi-square test $P=0.05$, Fig. 1g).

Interaction between site and origin

The Generalized Linear Model showed an origin $\times$ site interaction for the number of intact fruits 
Table 1 Generalized Linear Model analysing differences in various morphological and life history traits of plants from two different origins (dune/ inland), grown in two sites (dune/garden) (SPSS 15, Generalized Linear Models, type III Sums of Squares, all data were log-transformed)
Different populations are nested with origin. Error degrees of freedom $=86$

\begin{tabular}{|c|c|c|c|c|}
\hline Trait & Source & $d f$ & Wald statistic & $P$ \\
\hline \multirow[t]{4}{*}{ Number of stems } & Site & 1 & 120.88 & $P<0.001$ \\
\hline & Origin & 1 & 13.41 & $P<0.001$ \\
\hline & Pop(origin) & 3 & 6.27 & $P=0.10$ \\
\hline & Origin $\times$ site & 1 & 0.53 & $P=0.47$ \\
\hline \multirow[t]{4}{*}{ Stem height } & Site & 1 & 589.70 & $P<0.001$ \\
\hline & Origin & 1 & 6.83 & $P=0.009$ \\
\hline & Pop(origin) & 3 & 1.34 & $P=0.72$ \\
\hline & Origin $\times$ site & 1 & 2.73 & $P=0.10$ \\
\hline \multirow[t]{4}{*}{ Fruit number } & Site & 1 & 490.36 & $P<0.001$ \\
\hline & Origin & 1 & 6.43 & $P=0.011$ \\
\hline & Pop(origin) & 3 & 6.64 & $P=0.08$ \\
\hline & Origin $\times$ site & 1 & 0.07 & $P=0.78$ \\
\hline \multirow[t]{4}{*}{ Intact fruits } & Site & 1 & 463.98 & $P<0.001$ \\
\hline & Origin & 1 & 5.19 & $P=0.018$ \\
\hline & Pop(origin) & 3 & 3.69 & $P=0.32$ \\
\hline & Origin $\times$ site & 1 & 11.77 & $P<0.001$ \\
\hline \multirow[t]{4}{*}{$\%$ Damage by adult weevils } & Site & 1 & 244.54 & $P<0.001$ \\
\hline & Origin & 1 & 13.41 & $P<0.001$ \\
\hline & Pop(origin) & 3 & 5.86 & $P=0.12$ \\
\hline & Origin $x$ & 1 & 11.92 & $P=0.001$ \\
\hline \multirow[t]{4}{*}{ \% Damage by weevil larvae } & Site & 1 & 66.27 & $P<0.001$ \\
\hline & Origin & 1 & 23.86 & $P<0.001$ \\
\hline & Pop(origin) & 3 & 11.27 & $P=0.010$ \\
\hline & Origin $\times$ site & 1 & 0.83 & $P=0.36$ \\
\hline \multirow[t]{4}{*}{ Fitness } & Site & 1 & 541.72 & $P<0.001$ \\
\hline & Origin & 1 & 7.33 & $P=0.007$ \\
\hline & Pop(origin) & 3 & 5.36 & $P=0.147$ \\
\hline & Origin $\times$ site & 1 & 17.38 & $P<0.001$ \\
\hline
\end{tabular}

between dune and inland plants is only marginal and not significant (Table 2). Differences between populations within the dune origin or within the inland origin are not significant (Table 2). The data indicate local adaptation (Kawecki and Ebert 2004) in the dune habitat (Table 2). However, fitness differences are only marginal and insignificant in the garden.

\section{Discussion}

There is a main effect of origin on fitness, which means that overall dune plants do slightly better. In addition, the interaction between origin and site is highly significant (Table 1). When grown in the dunes, dune plants perform better than inland plants. When grown in the garden the fitness difference
We found many differences between A. thaliana plants originating from ecologically different habitats (dunes versus ruderal inland populations), which are persisted when plants were grown together in the only several kilometres apart. Since these differences 

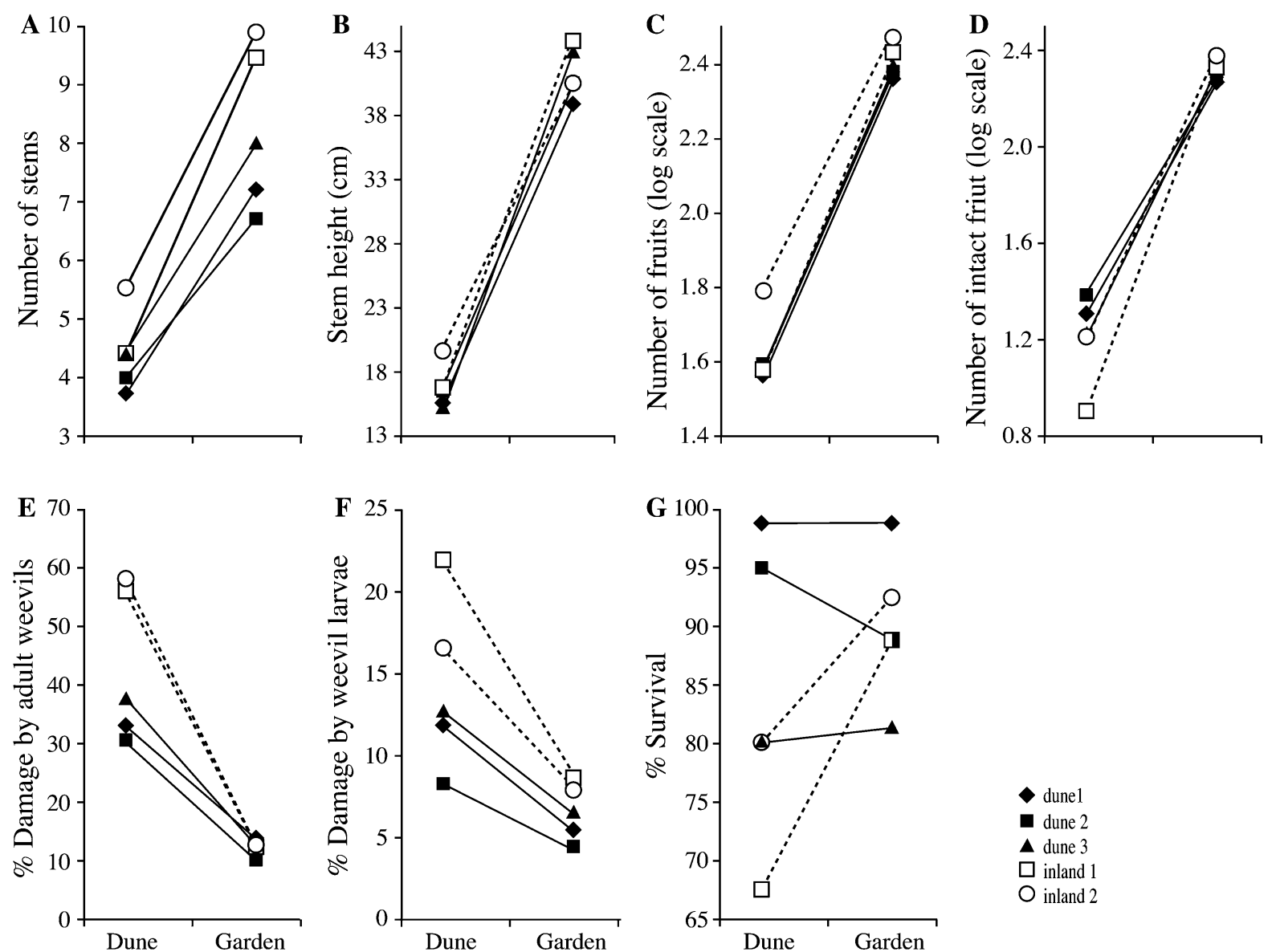

Fig. 1 Mean values for a number of stems, b stem height (cm), $\mathbf{c}$ total number of fruits, $\mathbf{d}$ number of intact fruits, $\mathbf{e} \%$ flowers damaged by adult weevils, f $\%$ damaged by weevil larvae, and $\mathbf{g} \%$ survival, for plants originating from 5

same habitat, the differences have at least partly a genetic background. It is an interesting finding that plants of dune origin are more plastic than plants of inland origin. This might suggest adaptation to the

Table 2 Log-transformed differences in fitness (see text for explanation) between plants derived from different populations nested with dune or inland origin when transplanted into a dune or garden site (95\%-CL, $n=10)$

\begin{tabular}{lll}
\hline Origin $\Downarrow$ & Dune site & Garden site \\
\hline Dune 1 & $1.27(0.12)$ & $2.22(0.11)$ \\
Dune 2 & $1.34(0.14)$ & $2.23(0.13)$ \\
Dune 3 & $1.12(0.15)$ & $2.23(0.12)$ \\
Inland 1 & $0.76(0.24)$ & $2.28(0.11)$ \\
Inland 2 & $1.01(0.27)$ & $2.32(0.11)$ \\
\hline
\end{tabular}

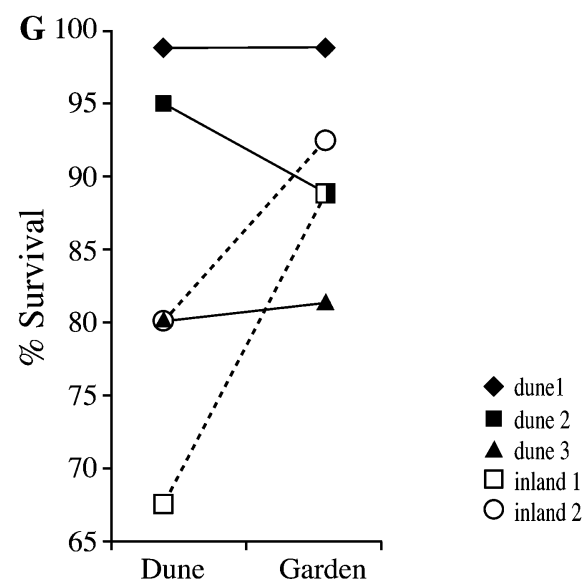

populations of Arabidopsis thaliana (3 in dunes, 2 in inland) when plants were grown in two habitats (dune and an inland garden)

dune habitat, which is, over the long run, perhaps more stable than the inland habitats with strong and unpredictable human disturbance.

Dune and inland plants showed consistent chemical differences. After growing plants in the lab for one generation we analyzed their chemical content by NMR spectroscopy and multivariate data analysis. These methods showed a clear separation between dune and inland genotypes based on metabolites (especially glucosinolates) in both seeds and leaves (Mosleh Arany et al. 2008). Glucosinolate concentrations were also typically higher in plants of dune origin.

The dune type was better defended against beetle herbivory. The mechanism behind the defence is, however, not yet clear. In crucifers glucosinolates are 
known to be involved in defence against herbivores. In a subsequent study (Mosleh Arany et al. 2008) we found differences in herbivory when plants of dune and inland plants were offered to larvae of generalist herbivore Spodoptera exigua under standard lab conditions. The larvae ate less from the dune plants, which may be due to their higher glucosinolate level. However, the feeding of Ceutorhynchus in the field appeared uncorrelated to glucosinolate content (Mosleh Arany 2006), suggesting that other factors play a role in plant defence against this specialist.

It is of interest to compare our results with those collected on other species in the Brassicaceae. Over small distances $(<15 \mathrm{~km})$ Brassica oleracea populations growing along the Atlantic coastlines of Great Britain and France, differed in glucosinolate content and composition, which correlated negatively with herbivore performance (Gols et al. 2008). In an earlier study, Mithen et al. (1995) reported up to a tenfold difference in glucosinolate composition between $B$. oleracea plants in different habitats. They ascribed this difference to selection for high glucosinolates in habitats with generalist herbivores and to selection for low glucosinolates in habitats with specialist herbivores. Moyes and Raybould (2001) found that the seed-eating beetle Ceutorhynchus assimilis did not oviposit on Brassica nigra but did on B. oleracea, regardless of the glucosinolate profiles of the individual plants.

We did not record date of first flowering for individual $A$. thaliana plants, but noticed that plants of dune origin flowered about a week later than plants from inland origin. Since the weevils were feeding most conspicuously on the plants towards the end of the experiment when few flowers were left, we think that late flowering of dune plants does not explain why they have less herbivory. It is rather the opposite, if dune plants would have flowered at the same time as inland plants, they probably would have even less herbivory and the effect of origin on herbivory would have been even higher. Furthermore, we did not collect data on the number of remaining seeds per fruit for plants of different origin, but instead used for all plants an average of $20 \%$ seed survival that was established in a previous year in the dune population (Mosleh Arany et al. 2005). It is conceivable that beetle larvae leave fewer seeds uneaten before they depart from a fruit on an inland plant. Such a difference would increase the difference in herbivory levels between plants of dune and inland origin. Clearly more detailed observations are needed here to understand the mechanism behind plant defence.

Herbivory was consistently higher in the dunes, and plants of dune origin were less eaten than plants of inland origin. We suggest this is due to a history of selection exerted by the beetles. However, conditions in dunes and inland differ in many respects and other selective factors may well have played a role. To test the hypothesis that the beetles are indeed the main selective factor, one would have to monitor seed herbivory in a large number of European A. thaliana populations and relate these measurements to plant characters. If high levels of field herbivory correlate positively with plant defence under standard conditions, this would strengthen our tentative suggestion that the specialist beetles indeed drive selection for plant defence in A. thaliana. Similar questions have been addressed for Brassica species and their herbivores. The model species A. thaliana has the advantage that it flowers early and is not affected by the many cabbage butterflies that attack the later flowering Brassica species. This would make the Arabidopsis system simpler and perhaps suited for studying the controversial role of specialist herbivores on evolution of plant defence.

Acknowledgements The authors thank Theodoor Heijerman from Wageningen University for identification of the Ceutorhynchus species. Duinwaterbedrijf Zuid Holland provided permits to work in the Meijendel area and kindly helped with the fieldwork

Open Access This article is distributed under the terms of the Creative Commons Attribution Noncommercial License which permits any noncommercial use, distribution, and reproduction in any medium, provided the original author(s) and source are credited.

\section{References}

Antlfinger AE (1981) The genetic basis of micro differentiation in natural and experimental populations of Borrichia frutescens in relation to salinity. Evolution 35:1056-1063. doi: $10.2307 / 2408120$

Antonovics J, Primack RB (1982) Experimental ecological genetics in Plantago VI. The demography of seedling transplants of $P$. lanceolata. J Ecol 70:55-75. doi:10.2307/ 2259864

Bergelson J, Stahl E, Dudek S et al (1998) Genetic variation within and among populations of Arabidopsis thaliana. Genetics 148:1311-1323 
Clausen J, Keck DD, Hiesey WM (1940) Experimental studies on the nature of species. I. Effect of varied environments on western North American plants. Carnegie Institution of Washington, Publication 581, Washington, DC

Clausen J, Keck DD, Hiesey WM (1948) Experimental studies on the nature of species. III. Environmental responses of climate races of Achillea. Carnegie Institution of Washington, Publication 520, Washington, DC

Farris MA (1987) Natural selection on the plant-water relations of Cleome serrulata growing along natural moisture gradients. Oecologia 72:434-439. doi:10.1007/BF00377576

Freude H, Harde KW, Lohse GA (1983) Die Käfer Mitteleuropas, Band 11. Goecke \& Evers, Krefeld

Gols R, Wagenaar R, Bukovinszky T et al (2008) Genetic variation in defense chemistry in wild cabbages affects herbivores and their endoparasites. Ecology 89:16161626. doi:10.1890/07-0873.1

Griffing B, Scholl RL (1991) Qualitative and quantitative genetic studies of Arabidopsis thaliana. Genetics 129:605-609

Griffith C, Kim E, Donohue K (2004) Life-history variation and adaptation in the historically mobile plant Arabidopsis thaliana (Brassicaceae) in North America. Am J Bot 91:837-849. doi:10.3732/ajb.91.6.837

Gurevitch J, Teeri JA, Wood AM (1986) Differentiation among populations of Sedum wrightii (Crassulaceae) in response to limited water availability: water relations, $\mathrm{CO}_{2}$ assimilation, growth and survivorship. Oecologia 70:198-204. doi:10.1007/BF00379240

Harvey JA, Witjes LMA, Benkirane M et al (2007) Nutritional suitability and ecological relevance of Arabidopsis thaliana and Brassica oleracea as foodplants for the cabbage butterfly, Pieris rapae. Plant Ecol 189:117-126. doi: 10.1007/s11258-006-9204-6

Jorgensen S, Mauricio R (2004) Neutral genetic variation among wild North American populations of the weedy plant Arabidopsis thaliana is not geographically structured. Mol Ecol 13:3403-3413. doi:10.1111/j.1365-294X. 2004.02329.x

Kaltz O, Gandon S, Michalakis Y et al (1999) Local maladaptation in the anther-smut fungus Microbotryum violaceum to its host plant Silene latifolia: evidence from a cross-inoculation experiment. Evolution 53:395-407. doi: $10.2307 / 2640776$

Kawecki T, Ebert D (2004) Conceptual issues in local adaptation. Ecol Lett 7:1225-1241. doi:10.1111/j.1461-0248. 2004.00684.xds

Koornneef M, Alonso-Blanco C, Vreugdenhil D (2004) Naturally occurring genetic variation in Arabidopsis thaliana. Annu Rev Plant Biol 55:141-172. doi:10.1146/annurev. arplant.55.031903.141605

Kover P, Schaal B (2002) Genetic variation for disease resistance among Arabidopsis thaliana ecotypes. Proc Natl Acad Sci USA 99:11270-11274. doi:10.1073/pnas.102288999

Linhart YB, Grant MC (1996) Evolutionary significance of local genetic differentiation in plants. Annu Rev Ecol Syst 27:237-277. doi:10.1146/annurev.ecolsys.27.1.237

Mauricio R (1998) Costs of resistance to natural enemies in field populations of the annual plant Arabidopsis thaliana. Am Nat 151:20-28. doi:10.1086/286099
McNeilly T, Antonovics J (1968) Evolution in closely adjacent plant populations. IV. Barriers to gene flow. Heredity 23:205-218. doi:10.1038/hdy.1968.29

Mitchell-Olds T (2001) Arabidopsis thaliana and its wild relatives: A model system for ecology and evolution. Trends Ecol Evol 16:693-699. doi:10.1016/S0169-5347(01) 02291-1

Mithen R, Raybould AF, Giamoustaris A (1995) Divergent selection for secondary metabolites between wild populations of Brassica oleracea and its implications for plantherbivore interactions. Heredity 75:472-484. doi:10.1038/ hdy. 1995.164

Mooney HA, Billings WD (1961) Comparative physiological ecology of arctic and alpine populations of Oxyria digyna. Ecol Monogr 31:1-29. doi:10.2307/1950744

Mosleh Arany A (2006) Ecology of Arabidopsis thaliana: local adaptation and interaction with herbivores. Thesis, Leiden University, the Netherlands, https://openaccess.leiden univ.nl/handle/1887/3771

Mosleh Arany A, de Jong TJ, van der Meijden E (2005) Herbivory and abiotic factors affect population dynamics of Arabidopsis thaliana in a sand-dune area. Plant Biol 7:549-556. doi:10.1055/s-2005-865831

Mosleh Arany A, de Jong TJ, Kim HK et al (2008) Glucosinolates and other metabolites in the leaves of Arabidopsis thaliana and their effects on a generalist and specialist herbivore. Chemoecology 18:65-72. doi:10.1007/s00049007-0394-8

Moyes CL, Raybould AF (2001) The role of spatial scale and intraspecific variation in secondary chemistry in hostplant location by Ceutorhynchus assimili (Coleoptera: Curculionidae). Proc R Soc Lond B Biol Sci 268:15671573. doi:10.1098/rspb.2001.1685

Murren CJ, Denning W, Pigliucci M (2005) Relationships between vegetative and life history traits and fitness in a novel field environment: impacts of herbivores. Evol Ecol 19:583-601. doi:10.1007/s10682-005-2005-x

Nordborg M, Bergelson J (1999) The effect of seed and rosette cold treatment on germination and flowering time in some Arabidopsis thaliana (Brassicaceae) ecotypes. Am J Bot 86:470-475. doi:10.2307/2656807

Nordborg M, Hu TT, Yoko I et al (2005) The pattern of polymorphism in Arabidopsis thaliana. PLOS Biology 3:1289-1299, e196

Nunez-Farfan J, Fornoni J, Valverde PL (2007) The evolution of resistance and tolerance to herbivores. Annu Rev Ecol Evol Syst 38:541-566. doi:10.1146/annurev.ecolsys.38. 091206.095822

Pigliucci M (1998) Ecological and evolutionary genetics of Arabidopsis. Trends Plant Sci 3:485-489. doi:10.1016/ S1360-1385(98)01343-0

Pigliucci M, Marlow ET (2001) Differentiation of flowering time and phenotypic integration in Arabidopsis thaliana in response to season length and vernalization. Oecologia 127:501-508. doi:10.1007/s004420000613

Prins AH (1989) Herbivory and plant performance of Senecio jacobaea L. and Cynoglossum officinale L. Ph.D. Thesis. Leiden University

Ratcliffe D (1961) Adaptation to habitat in a group of annual plants. J Ecol 49:187-203. doi:10.2307/2257433 
Rice KJ, Mack RN (1991) Ecological genetics of Bromus tectorum III The demography of reciprocally sown populations. Oecologia 88:91-101. doi:10.1007/BF00328408

Schoen DJ, Stewart SC, Lechowicz MJ et al (1986) Partitioning the transplant site effect in reciprocal transplant experiments with Impatiens capensis and Impatiens pallida. Oecologia 70:149-154. doi:10.1007/BF00377125

Snaydon RW (1970) Rapid population differentiation in a mosaic environment. I. The response of Anthoxanthum odoratum populations to soils. Evolution 24:257-269. doi: 10.2307/2406802

Thrall PH, Burdon JJ, Bever JD (2002) Local adaptation in the Linum marginale-Melampsoria lini host-pathogen interaction. Evolution 56:1340-1351

Turkington R, Harper JL (1979) The growth, distribution and neighbor relationships of Trifolium repens in a permanent pasture. IV. Fine-scale biotic differentiation. J Ecol 67:245-254. doi:10.2307/2259348

Valverde PL, Fornoni J, Nunez-Farfan J (2003) Evolutionary ecology of Datura stramonium: equal plant fitness benefits of growth and resistance against herbivory. J Evol Biol 16:17-137. doi:10.1046/j.1420-9101.2003.00482.x

van der Meijden E (1996) Plant defence, an evolutionary dilemma: contrasting effects of (specialist and generalist) herbivores and natural enemies. Entomol Exp Appl 80:307-310. doi:10.1007/BF00194780

Weinig C, Stinchcombe JR, Schmitt J (2003) Evolutionary genetics of resistance and tolerance to natural herbivory in Arabidopsis thaliana. Evolution 57:1270-1280 